\title{
Publicações sobre o ensino de Física Moderna: relações construídas entre
} Artes e Física ${ }^{+*}$

Aline dos Santos Silva ${ }^{1}$

Centro Federal de Educação Tecnológica Celso Suckow da Fonseca José Claudio de Oliveira Reis ${ }^{1}$

Centro Federal de Educação Tecnológica Celso Suckow da Fonseca

Universidade do Estado do Rio de Janeiro

Sheila Cristina Ribeiro Rego ${ }^{1}$

Centro Federal de Educação Tecnológica Celso Suckow da Fonseca

Rio de Janeiro - RJ

\section{Resumo}

A disciplina de Física ser considerada como uma das mais difíceis em relação à compreensão por parte dos alunos não é novidade em pesquisas educacionais. Essa dificuldade é ampliada quando a Física Moderna entra em cena, devido ao seu elevado grau de abstração. Relacionar a Arte com a Física se mostra como uma boa alternativa para esse problema. Com a intenção de compreender mais sobre a conexão entre Artes e Física, realizamos uma pesquisa bibliográfica a fim de verificar de que modo elas podem se relacionar no ensino de Física Moderna, constatando que, na maioria dos casos, a Arte é utilizada como ferramenta facilitadora no ensino dos conceitos presentes na Física Moderna.

Palavras-chave: Física Moderna; Arte; Ensino de Física.

\begin{abstract}
The discipline of physics being considered one of the most difficult in relation to student understanding is not new in educational research. This difficulty is amplified when Modern Physics enters the scene, due to

\footnotetext{
+ Publications on the teaching of Modern Physics: relations built between Arts and Physics

* Recebido: dezembro de 2018. Aceito: junho de 2019.

${ }^{1}$ E-mails: aline.s_santos@mail.com; joseclaudioreis63@gmail.com; scrrego@gmail.com
} 
its high degree of abstraction. Relating Art to Physics is a good alternative to this problem. With the intention of understanding more about the connection between Arts and Physics, we carried out a bibliographical research in order to verify how they can relate in the teaching of Modern Physics, noting that, in most cases, Art is used as a facilitating tool in the teaching of the concepts present in Modern Physics.

Keywords: Modern Physics; Art; Physics Teaching.

\section{Introdução}

A disciplina de Física ser considerada como uma das mais difíceis em relação à compreensão por parte dos alunos não é novidade em pesquisas educacionais (RICARDO; FREIRE, 2007; MONTEIRO; NARDI; BASTOS FILHO, 2009). Essa dificuldade já se mostra presente em assuntos relacionados à Física Clássica e é ampliada quando a Física Moderna entra em cena, visto que esta última exige um grau de abstração mais elevado, principalmente por possuir certos objetos de estudo que não são visíveis a olho nu. O problema da abstração e, consequentemente, do entendimento dos conceitos presentes na Física Moderna não se restringe apenas aos alunos, se estendendo aos próprios professores (MONTEIRO; NARDI; BASTOS FILHO, 2009).

Diversos estudos foram realizados com o objetivo de entender os obstáculos encontrados na inserção da Física Moderna no ensino médio (MACHADO; NARDI, 2003; OLIVEIRA; VIANNA; GERBASSI, 2007; MONTEIRO; NARDI; BASTOS FILHO, 2009). Em geral, além do grau de abstração exigido, podemos destacar como principais obstáculos o formalismo matemático, a programação escolar voltada para o vestibular e a deficiência na formação do próprio professor.

Ao mesmo tempo em que devemos nos voltar para estudos sobre as barreiras que impedem que esse conteúdo chegue de maneira satisfatória aos alunos, devemos olhar para as possíveis soluções que novas práticas de ensino proporcionam. Práticas que unem conhecimentos de diversas áreas de forma contextualizada, utilizando elementos particulares dessas áreas como representações de conceitos estudados na Física Moderna.

Uma conexão interessante é a que ocorre entre a Física e a Arte. Essa relação entre as duas áreas de ensino, consideradas opostas e sem ligação, tem sido explorada e também aplicada dentro da área de ensino (REIS; GUERRA; BRAGA, 2006; ZANETIC, 2006; CACHAPUZ, 2014). Para Zanetic (2006), o ensino de Física não pode dispensar a história da Física e sua ligação com outras áreas culturais, como, por exemplo, o cinema, o teatro e a literatura. A Arte então pode ser inserida de modo mais aprofundado, garantindo uma conexão histórica e social entre os conceitos e técnicas estudados.

Essa conexão histórica e social é realizada por Reis, Guerra e Braga (2006), ao mos- 
trarem a relação entre Ciência e Arte com o objetivo de apresentar a Ciência através de uma abordagem cultural, tornando a compreensão de seus conteúdos mais significativa. Os autores acreditam que esse tipo de abordagem, além de auxiliar na compreensão, “[...] poderá ajudar a entender que a ciência é um produto sociocultural e, como tal, deve ser apreendida" (REIS; GUERRA; BRAGA, 2006, p. 84).

A interdisciplinaridade é defendida por Cachapuz (2014) que nos diz que "uma maneira possível de nos tornarmos mais humanos é aproximar o 'mundo da verdade' do 'mundo da emoção e da beleza"” (p. 97). O autor considera a interdisciplinaridade entre Arte e Ciência como parte do problema na sua transposição para a prática, assim como as políticas enviesadas que confundem educação com instrução, a falta de materiais didáticos e a formação inadequada de professores. Assim, o autor apresenta exemplos de transposições realizadas por ele e por outros autores com uso de artes pictóricas e poemas no ensino de ciências.

Com a intenção de compreender mais sobre essa conexão entre a Física e a Arte, pretendemos, após uma breve exposição histórica dessa conexão, responder ao seguinte questionamento: de que modo a Arte e a Física se relacionam no ensino de Física Moderna?

Para isso, realizamos uma pesquisa bibliográfica em periódicos da área de ensino e em anais de eventos sobre ensino de Física a fim de conhecer o material já produzido sobre o tema em questão, realizando, posteriormente, uma análise das abordagens dos artigos, que nos auxiliou a compreender como se dá a relação entre essas duas áreas nas publicações referentes ao ensino de Física.

\section{Ciência, Arte e Ensino}

Ciência e Arte são áreas de conhecimento que, de certa forma, se complementam desde a antiguidade, mesmo que a primeira seja relacionada à razão e a segunda à emoção. Na cosmologia da Idade Média havia a divisão do universo em dois mundos incomunicáveis, o sublunar e o supralunar. Na pintura da época, essa divisão também se fazia presente, sendo o céu e a terra representados de forma descontínua (REIS; GUERRA; BRAGA, 2006).

No Renascimento, novas técnicas artísticas foram introduzidas na pintura, como a perspectiva e os efeitos de luz e sombra. O conhecimento dessas técnicas adquiridas por Galileu em Florença auxiliou em seus desenhos de observações da Lua, mostrando que a mesma possuía imperfeições antes consideradas impossíveis, diferenciando seu trabalho dos desenhos feitos pelo astrônomo Thomas Harriot, na mesma época, realizados sem o conhecimento de tais técnicas (REIS; GUERRA; BRAGA, 2006).

Artistas e cientistas trabalhavam em conjunto, sendo os primeiros responsáveis pelas ilustrações das observações realizadas pelos segundos, a fim de complementar os textos científicos, principalmente nas áreas de Biologia e Medicina (ROSSI, 2001). Como Reis, Guerra e Braga (2006) escrevem, "Artistas e cientistas (ou filósofos naturais) percebem o mundo da mesma forma, apenas representam-no com linguagens diferentes” (p. 72).

Técnicas do campo da óptica começaram a ser usadas nas pinturas, que, por isso, pa- 
reciam mais reais e naturais. Artistas utilizavam câmeras lúcidas e câmeras escuras para a projeção das imagens a serem pintadas, deixando como característica a projeção invertida da imagem, como, por exemplo, pessoas segurando objetos com a mão esquerda, o que não era comum na época. Os espelhos convexos aparecem em algumas pinturas dos séculos XV e XVII, dando indícios de que os artistas tinham conhecimento desses objetos e os utilizavam como auxiliares no processo de composição de suas obras (ALCANTARA; BRAGA; COSTA, 2017; BARBOSA-LIMA; QUEIROZ; SANTIAGO, 2007).

Na mudança do século XIX para o século XX, a Física e a Arte entram em um novo e complexo modo de ver o mundo. O surgimento da Mecânica Quântica e da Teoria da Relatividade mostrou que o conhecimento do mundo físico não estava finalizado, como acreditavam os cientistas do século XIX, e abriram caminhos para novas interpretações sobre o espaço, o tempo, a simultaneidade, a localidade e a causalidade.

No século XX surge o Surrealismo, movimento artístico iniciado na França em 1924 por André Breton. Nesse estilo artístico, a característica predominante é a ausência de lógica. Os artistas fogem do senso comum até então presente nas obras de outros estilos e passam a exprimir o irreal, o sonho, o impossível. Objetos conhecidos pelos observadores são postos em situações não convencionais, causando grande impacto e certo desconforto ao fugir da nossa compreensão de realidade. Como mostram Reis, Guerra e Braga (2006, p. 78),

Em certa medida, o aparecimento de uma arte impenetrável tem uma ligação com o surgimento de uma ciência que também desnorteou o público das suas noções básicas da realidade. [...] O Surrealismo, por exemplo, surgiu procurando sonhar e agir, superando a dicotomia que essas ações representam. Há uma negação da consciência, um abandono do controle da razão sobre o ato criativo.

O contexto histórico onde essas duas áreas estão inseridas nos permite fazer uma ligação entre elas, ligação essa já defendida por C. P. Snow, há quase 60 anos, em seu debate sobre as duas culturas, a científica e a humanística. Em suas palavras sobre a polarização dessas culturas "[...] é pura perda para todos nós. Para nós como pessoas, e para a nossa sociedade. É ao mesmo tempo perda prática, perda intelectual e perda criativa, e repito que é errôneo imaginar que esses três aspectos são claramente separáveis" (SNOW, 1995, p. 29).

A fuga dessa polarização abre portas para trabalharmos essa relação de modo a aprimorar o conhecimento, tornando-o mais significativo e proporcionando ao aluno uma forma mais complexa de ver a realidade.

No ensino, essa relação vem sendo explorada com o intuito de tornar o aprendizado mais contextualizado, proporcionando aulas diferenciadas das tradicionais, comuns no ensino de Física. Galili (2013) destaca que, com o avanço do curso de Física, ocorre a abstração de imagens utilizadas no material didático, assim, quanto mais avançados os cursos, menos imagens pictóricas se fazem presentes, sendo estas substituídas por esquemas de experimentos, gráficos e fórmulas. A partir desse ponto, o autor mostra a importância de imagens pictóricas para a construção mental do assunto que o aluno está aprendendo, partindo do princípio de 
que com a visualização de uma imagem que represente o que está sendo apresentado, o aluno absorve melhor o conteúdo.

A literatura e a música são modalidades utilizadas por Zanetic (2006) para ilustrar a ponte entre a Física e a Arte, tendo como objetivo central atingir os alunos que não se sentem motivados a estudar Física. A leitura e a interpretação das letras das músicas abrem caminhos para o estudo de conceitos científicos presentes em sua composição. $\mathrm{O}$ autor ressalta que para trabalhar com obras literárias de ficção científica o professor deve ter o devido cuidado com os obstáculos epistemológicos que elas possuem, problematizando-os com os alunos e tornando a experiência educacional mais enriquecida.

\section{Metodologia}

A investigação constitui uma pesquisa bibliográfica, visto que esta metodologia permite que o pesquisador possua uma cobertura sobre o assunto mais ampla do que aquela que ele poderia obter ao pesquisar de forma direta (GIL, 2002). Para compor a pesquisa, foi realizada a busca por publicações que abordam a temática das Artes no Ensino de Física Moderna em 12 periódicos brasileiros da área de ensino de Física e ensino de Ciências, selecionados a partir do Qualis da Capes (Coordenação de Aperfeiçoamento de Pessoal de Nível Superior), disponível na Plataforma da Capes, sendo considerados os periódicos de Qualis A1 até o Qualis $\mathrm{B} 2^{2}$. Para este trabalho não foi estipulado um período de busca nos periódicos, sendo pesquisados todos os volumes disponíveis para download.

Também foi realizada a consulta aos anais do Encontro Nacional de Pesquisa em Educação em Ciências (ENPEC) - no período de 2011 a 2017 - e do Simpósio Nacional de Ensino de Física (SNEF) - no período de 2005 a 2015.

Os periódicos consultados foram: Revista Brasileira de Ensino de Física; Ciência \& Educação; Caderno Brasileiro de Ensino de Física (incluindo as publicações em nome do Caderno Catarinense de Ensino de Física, nome inicial do periódico até 2002); Investigações em Ensino de Ciências; Ensaio: Pesquisa em Educação em Ciências; Revista Brasileira de Pesquisa em Educação em Ciências; Revista Educação, Ciências e Matemática; Ciência em Tela; Ensino \& Pesquisa; Ciência e Ensino; Alexandria: Revista de Educação em Ciência e Tecnologia; Experiências em Ensino de Ciências.

A pesquisa das publicações foi realizada através da ferramenta de busca presente na plataforma de cada periódico, com a utilização das palavras-chave "Física"; "Física Moderna"; "Física e Arte"; "Ciência e Arte"; "Arte"; "Física Quântica”; "Teoria Quântica”; "Relatividade"; "Quântica"; "Radioatividade" e "Raios X" como filtros de pesquisa. Apenas dois periódicos não possuíam a ferramenta de busca, sendo necessário pesquisar manualmente os

\footnotetext{
2 Pesquisa realizada em março de 2018 através do endereço eletrônico:

$<$ https://sucupira.capes.gov.br/sucupira/public/consultas/coleta/veiculoPublicacaoQualis/listaConsultaGeralPerio dicos.jsf>.
} 
volumes disponibilizados.

Já a pesquisa nos anais dos eventos selecionados foi feita a partir dos eixos temáticos. No ENPEC, foram pesquisadas as áreas "Processos e materiais educativos na educação em Ciências"; "Questões teóricas e metodológicas da pesquisa em educação em Ciências"; Linguagens, discurso e educação em Ciências"; "História, Filosofia e Sociologia da Ciência na educação em Ciências" e "Ensino e aprendizagem de conceitos científicos". No SNEF foi pesquisada a área de "Ciência, cultura e Arte" que, até o ano de 2009, recebia o nome de "Arte, cultura e Educação Científica".

Em ambos os casos, a triagem dos artigos que comporiam a amostra final foi feita a partir da leitura dos títulos, sendo selecionados aqueles que contemplavam a temática de interesse. Após essa triagem inicial, foram lidos os resumos para uma segunda seleção a fim de eliminar aqueles que não abordavam a temática diretamente. Ao finalizar as pesquisas descritas acima, foi obtida uma amostra com 9 artigos de periódicos e 11 trabalhos de eventos, totalizando 20 publicações, listadas e numeradas nos quadros abaixo.

Quadro 1 - Listagem das publicações dos periódicos.

\begin{tabular}{|c|c|c|c|}
\hline Artigo & Título (Autores) & Periódico & Ano \\
\hline 1 & $\begin{array}{l}\text { É possível levar a Física Quântica para o Ensino Mé- } \\
\text { dio? (PINTO, A. C.; ZANETIC, J.) }\end{array}$ & $\begin{array}{l}\text { Caderno Catarinense de En- } \\
\text { sino de Física }\end{array}$ & 1999 \\
\hline 2 & $\begin{array}{l}\text { Influências da Física Moderna na obra de Salvador } \\
\text { Dalí (ANDRADE, R. R. D. de; NASCIMENTO, R. de } \\
\text { S.; GERMANO, M. G.) }\end{array}$ & $\begin{array}{l}\text { Caderno Brasileiro de Ensino } \\
\text { de Física }\end{array}$ & 2007 \\
\hline 3 & $\begin{array}{l}\text { Teoria da relatividade restrita e geral no programa de } \\
\text { mecânica do ensino médio: uma possível abordagem } \\
\text { (GUERRA, A.; BRAGA, M.; REIS, J. C.) }\end{array}$ & $\begin{array}{l}\text { Revista Brasileira de Ensino } \\
\text { de Física }\end{array}$ & 2007 \\
\hline 4 & $\begin{array}{l}\text { Física Moderna no Ensino Médio: o Espaço-Tempo de } \\
\text { Einstein em tirinhas (CARUSO, F.; FREITAS, N. de) }\end{array}$ & $\begin{array}{l}\text { Caderno Brasileiro de Ensino } \\
\text { de Física }\end{array}$ & 2009 \\
\hline 5 & $\begin{array}{l}\text { Física e pintura: dimensões de uma relação e suas } \\
\text { potencialidades no ensino de Física (GOMES, T. C.; } \\
\text { DI GIORGI, C. A. G.; RABONI, P. C. de A.) }\end{array}$ & $\begin{array}{l}\text { Revista Brasileira de Ensino } \\
\text { de Física }\end{array}$ & 2011 \\
\hline 6 & $\begin{array}{l}\text { Einstein e a Relatividade entram em cena: diálogos } \\
\text { sobre o teatro na escola e um ensino de Física criativo } \\
\text { (OLIVEIRA, L.M.; GOMES, M. L. A.) }\end{array}$ & $\begin{array}{l}\text { Caderno Brasileiro de Ensino } \\
\text { de Física }\end{array}$ & 2016 \\
\hline
\end{tabular}




\begin{tabular}{|l|l|l|l|}
\hline 7 & $\begin{array}{l}\text { O livro paradidático no ensino de Física - uma análise } \\
\text { fabular, científica e metafórica da obra Alice no País } \\
\text { do Quantum: a Física Quântica ao alcance de todos } \\
\text { (SOUZA, A. R. de; NEVES, L. A. dos S.) }\end{array}$ & $\begin{array}{l}\text { Caderno Brasileiro de Ensino } \\
\text { de Física }\end{array}$ & 2016 \\
\hline $\mathbf{8}$ & $\begin{array}{l}\text { O insólito e a física moderna: interfaces didáticas do } \\
\text { conto fantástico (RAMOS, J. E. F.; PIASSI, L. P.) }\end{array}$ & Ciência e Educação & 2017 \\
\hline $\mathbf{9}$ & $\begin{array}{l}\text { Pinturas de Salvador Dalí para introduzir conceitos de } \\
\text { Mecânica Quântica no Ensino Médio (FERNANDES, } \\
\text { R. de F. A. M.; PIRES, F. F.; FORATO, T. C. de M.; } \\
\text { SILVA, J. A. da) }\end{array}$ & $\begin{array}{l}\text { Caderno Brasileiro de Ensino } \\
\text { de Física }\end{array}$ & 2017 \\
\hline
\end{tabular}

Quadro 2 - Listagem das publicações dos eventos.

\begin{tabular}{|c|c|c|c|}
\hline Artigo & Título (Autores) & Evento & Ano \\
\hline 10 & $\begin{array}{l}\text { Ciência e Arte, Razão e Imaginação: um projeto de } \\
\text { ensino de Física Moderna para alunos do ensino médio } \\
\text { (CARVALHO, S. H. M. de; ZANETIC, J.) }\end{array}$ & XVI SNEF & 2005 \\
\hline 11 & $\begin{array}{l}\text { Influência da Teoria da Relatividade na obra de Salva- } \\
\text { dor Dalí (ANDRADE, R. R. D. de; NASCIMENTO, } \\
\text { R. de S.; GERMANO, M. G.) }\end{array}$ & XVI SNEF & 2005 \\
\hline 12 & $\begin{array}{l}\text { O Teatro e a Física: a cena que não entra em sala } \\
\text { (NORY, R. M.; ZANETIC, J.) }\end{array}$ & XVI SNEF & 2005 \\
\hline 13 & $\begin{array}{l}\text { Ciência e Arte: Razão e Sensibilidade (NUNES, A. L.; } \\
\text { TEIXEIRA, G. A.) }\end{array}$ & XVII SNEF & 2007 \\
\hline 14 & $\begin{array}{l}\text { Física e Literatura: intersecções possíveis em sala de } \\
\text { aula (MENEZES, A. M. S.; MORAES, A. G. de) }\end{array}$ & XVIII SNEF & 2009 \\
\hline 15 & $\begin{array}{l}\text { Ciência, cinema e macacos (SANTOS, G. L. dos; } \\
\text { TEIXEIRA, R. R. P.) }\end{array}$ & XX SNEF & 2013 \\
\hline 16 & $\begin{array}{l}\text { Poesia e Física: multiplicando a beleza das coisas } \\
\text { (BARJA, P. R.) }\end{array}$ & XX SNEF & 2013 \\
\hline
\end{tabular}




\begin{tabular}{|l|l|l|l|}
\hline $\mathbf{1 7}$ & $\begin{array}{l}\text { Perspectivas socioculturais no uso da canção no ensino } \\
\text { de Física: utilizando o rock para debater questões ine- } \\
\text { rentes às missões espaciais e aos paradoxos temporais } \\
\text { (GOMES, E. F.; PIASSI, L. P.; FERNANDES, J.) }\end{array}$ & XX SNEF & 2013 \\
\hline $\mathbf{1 8}$ & $\begin{array}{l}\text { Ciência, mídia e educação: possíveis confluências no } \\
\text { ensino de Física (GOMES, E. F.; PIASSI, L. P. de C.) }\end{array}$ & XXI SNEF & 2015 \\
\hline $\mathbf{1 9}$ & $\begin{array}{l}\text { Estabelecendo o diálogo entre as duas culturas: imagi- } \\
\text { nação e criatividade aliadas ao ensino de Física (OLI- } \\
\text { VEIRA, L. M. de) }\end{array}$ & XXI SNEF & 2015 \\
\hline $\mathbf{2 0}$ & $\begin{array}{l}\text { A rede social Pinterest e a curadoria na educação cien- } \\
\text { tífica: o exemplo do surrealismo de Dalí (EICHLER, T. } \\
\text { Z. N.; EICHLER, M. L.) }\end{array}$ & XI ENPEC & 2017 \\
\hline
\end{tabular}

Para facilitar a análise dos artigos, foram criadas três categorias em relação ao tipo de abordagem realizada. A primeira categoria, Proposta Didática, engloba os trabalhos que apresentam sugestões de possíveis aplicações em sala de aula. A segunda categoria, Abordagem Teórica, destina-se aos trabalhos que exploram historicamente e teoricamente a temática. A terceira categoria, Experiência Educacional, atende aos trabalhos de caráter expositivo de aplicações realizadas em sala de aula. Esta separação é mostrada no quadro 3, a seguir.

Quadro 3 - Artigos por categorias.

\begin{tabular}{|l|l|}
\hline Categoria & Artigos \\
\hline Proposta Didática & $4-7-9$ \\
\hline Abordagem Teórica & $2-5-8-11-12^{3}-13-16-18-20$ \\
\hline Experiência Educacional & $1-3-6-10-14-15-17-19$ \\
\hline
\end{tabular}

A análise de cada uma das três categorias criadas nos permite compreender como essa temática Arte e Física Moderna está sendo explorada e/ou aplicada pelos profissionais de ensino.

\footnotetext{
3 O texto do artigo 12 encontra-se incompleto, não apresentando as páginas de relação entre a física e os textos das peças de teatro trabalhadas, não sendo possível analisar os temas de física destacados pelos autores.
} 


\section{Análise}

Para uma melhor compreensão das informações fornecidas pelos artigos, foram criadas subcategorias com dados referentes ao tipo de produção artística utilizado, conceitos de Física Moderna abordados, nível de ensino, contexto de aplicação da produção artística e a relação dos sujeitos com a produção artística. Esses dados foram organizados nas tabelas a seguir, que os apresentam de acordo com cada categoria anteriormente apresentadas.

\section{Produção artística}

A tabela 1 apresenta os tipos de produção artística apresentados nos artigos. A partir dela, percebemos que a pintura e a literatura são as modalidades artísticas mais exploradas na amostra. Na pintura, notamos a presença, em sua maioria, de diversos quadros do pintor Salvador Dalí. A preferência por Dalí pode ser entendida por sua proximidade e interesse com a área científica, assim como pela presença de termos científicos nos nomes de algumas de suas obras.

Já o uso de obras literárias é justificado por alguns autores por apresentar o conteúdo a ser estudado de forma lúdica, trazendo uma aceitação mais fácil por parte do aluno-leitor. No geral, as produções artísticas encontradas exploram a interpretação por parte dos alunos, buscando a identificação de conceitos científicos presentes em seus conteúdos e a posterior discussão dos mesmos.

Tabela 1 - Tipos de produção artísticas.

\begin{tabular}{|c|c|c|c|c|}
\hline Produção artística & Proposta didática & $\begin{array}{l}\text { Abordagem teóri- } \\
\qquad a\end{array}$ & $\begin{array}{c}\text { Experiência edu- } \\
\text { cacional }\end{array}$ & Total de artigos \\
\hline Música & & 18 & 1,17 & 3 \\
\hline História em quadrinhos & 4 & & 1 & 2 \\
\hline Poesia & & 16 & 1,19 & 3 \\
\hline Pintura & 9 & $2,5,11,13,20$ & 3,19 & 8 \\
\hline Literatura & 7 & $8,13,18$ & $10,14,19$ & 7 \\
\hline Filme & & 18 & $3,10,15$ & 4 \\
\hline Teatro & & 12 & 6 & 2 \\
\hline Programas de $T V$ & & 18 & & 1 \\
\hline
\end{tabular}




\section{Conceitos de Física Moderna e Contemporânea}

A tabela II apresenta os principais tópicos de FMC abordados nos artigos analisados. As Teorias da Relatividade são as mais trabalhadas nesses artigos, seguidas da dualidade onda-partícula e do Princípio da incerteza. De forma mais específica, são trabalhados os conceitos de tempo, espaço, velocidade da luz, viagens no tempo, buracos de minhoca, estados quânticos, partículas elementares entre outros.

Tabela 2 - Conceitos de Física Moderna e Contemporânea.

\begin{tabular}{|c|c|c|c|c|}
\hline Conceitos de FMC & $\begin{array}{c}\text { Proposta didá- } \\
\text { tica }\end{array}$ & $\begin{array}{c}\text { Abordagem teó- } \\
\text { rica }\end{array}$ & $\begin{array}{c}\text { Experiência educa- } \\
\text { cional }\end{array}$ & $\begin{array}{l}\text { Total de arti- } \\
\text { gos }\end{array}$ \\
\hline $\begin{array}{c}\text { Dualidade onda- } \\
\text { partícula }\end{array}$ & 9 & $2,5,13$ & 1,10 & 6 \\
\hline $\begin{array}{c}\text { Teorias da Relati- } \\
\text { vidade }\end{array}$ & 4 & $2,5,11$ & $\begin{array}{c}3,6,10,14,15,17 \\
19\end{array}$ & 11 \\
\hline Modelo atômico & 9 & 2,20 & & 3 \\
\hline Quanta & 7,9 & $2,5,13$ & & 5 \\
\hline $\begin{array}{c}\text { Princípio da incer- } \\
\text { teza }\end{array}$ & 7,9 & $2,5,16$ & 19 & 6 \\
\hline $\begin{array}{c}\text { Matéria e anti- } \\
\text { matéria }\end{array}$ & 7 & & & 1 \\
\hline $\begin{array}{l}\text { Princípio de exclu- } \\
\text { são de Pauli }\end{array}$ & 7 & & & 1 \\
\hline Probabilidade & 7 & & & 1 \\
\hline Multiuniversos & & 8,18 & & 2 \\
\hline $\begin{array}{l}\text { Superposição de } \\
\text { estados quânticos }\end{array}$ & & 8,16 & & 2 \\
\hline
\end{tabular}

\section{Nível de ensino}

A tabela III mostra o nível de ensino onde a relação foi desenvolvida. Como era o esperado, o ensino médio foi o nível mais escolhido, justificado pelo fato de ser a modalidade onde a Física é mais trabalhada na formação básica. Encontramos, também, artigos que apresentam essa relação tanto para o nível médio quanto para o nível superior. (é interessante ver uma quantidade de trabalhos voltados para o nível superior, visto que a formação do profes- 
sor, na maioria das vezes, é citada como parte fundamental para que as mudanças desejadas no ensino sejam possíveis).

Tabela 3 - Nível de ensino.

\begin{tabular}{|c|c|c|c|c|}
\hline Nível de ensino & $\begin{array}{c}\text { Proposta didá- } \\
\text { tica }\end{array}$ & $\begin{array}{c}\text { Abordagem teó- } \\
\text { rica }\end{array}$ & $\begin{array}{c}\text { Experiência educa- } \\
\text { cional }\end{array}$ & $\begin{array}{c}\text { Total de arti- } \\
\text { gos }\end{array}$ \\
\hline Fundamental & & 8,16 & & $\mathbf{2}$ \\
\hline Médio & $4,7,9$ & $2,5,8,11,16$ & $1,3,6,10,14,15$ & $\mathbf{1 4}$ \\
\hline Superior & & $2,5,11,16$ & $15,17,19$ & $\mathbf{7}$ \\
\hline
\end{tabular}

\section{Contexto de aplicação}

A tabela IV apresenta como as modalidades artísticas foram trabalhadas em sala de aula. Em sua maioria, vemos a utilização das mesmas apenas como recurso introdutório para apresentação de conceitos ou identificação de elementos presentes na FMC. Obras de artistas surrealistas são comentadas como, por exemplo, A traição das imagens de René Magritte, por mostrar o poder das representações, assunto relevante para a Física Quântica que trabalha com elementos invisíveis aos nossos olhos. Em menor número, vemos a utilização das artes como método avaliativo, buscando a interpretação ou a criatividade dos alunos na exposição dos conteúdos estudados.

Tabela 4 - Contexto de aplicação.

\begin{tabular}{|c|c|c|c|c|}
\hline Contexto de aplicação & Proposta didática & $\begin{array}{c}\text { Abordagem teóri- } \\
\text { ca }\end{array}$ & $\begin{array}{c}\text { Experiência } \\
\text { educacional }\end{array}$ & Total de artigos \\
\hline $\begin{array}{r}\text { Introdução e discussão } \\
\text { de novos assuntos }\end{array}$ & $4,7,9$ & $2,16,20$ & $6,10,14,15$, & 12 \\
\hline Avaliação & 4 & 17,19 & \\
\hline $\begin{array}{r}\text { Atividades em sala de } \\
\text { aula }\end{array}$ & & 3,19 & $\mathbf{3}$ \\
\hline $\begin{array}{c}\text { Atividades extraclasses } \\
\text { (Feira de ciências, } \\
\text { semana cultural...) }\end{array}$ & & 3,17 & $\mathbf{2}$ \\
\hline
\end{tabular}




\section{Relação Sujeito x Produção artística}

A tabela $\mathrm{V}$ expõe como o sujeito se relaciona com a produção artística utilizada. Notamos que as relações encontradas na amostra se dão, em sua maioria, de maneira indireta, seja através da leitura ou da observação, a fim de interpretar e identificar elementos de FMC nas produções escolhidas. Em poucos casos observamos a criação de novas produções a partir do conhecimento apreendido durante as aulas.

Tabela 5 - Relação entre sujeito e produção artística.

\begin{tabular}{|c|c|c|c|c|}
\hline $\begin{array}{c}\text { Relação Sujeito } \boldsymbol{x} \\
\text { Produção artística }\end{array}$ & Proposta didática & Abordagem teórica & $\begin{array}{c}\text { Experiência edu- } \\
\text { cacional }\end{array}$ & Total de artigos \\
\hline Leitura & 7 & 8,12 & $10,14,17,19$ & 7 \\
\hline Criação & 4 & 16 & $1,3,6,10,19$ & 7 \\
\hline Observação & 4,9 & $2,11,20$ & $3,15,17,19$ & 9 \\
\hline
\end{tabular}

\section{Discussão}

Após a análise apresentada acima, foi verificado que, no geral, as modalidades de arte encontradas são bem diversificadas, sendo a literatura e pintura as mais utilizadas dentro da amostra. Entendemos esse destaque pelo poder de interpretação que essas duas modalidades oferecem, visto que cada leitor ou observador tem a liberdade de entendê-las de acordo com sua bagagem cultural. Quando usadas no ensino, o professor tem a possibilidade de incentivar a interpretação dessas obras por parte do aluno, mostrando as potencialidades de aproximação com outras áreas de ensino, auxiliando na contextualização da aprendizagem do aluno.

Sobre os conceitos de Física Moderna e Contemporânea abordados, destacamos as Teorias da Relatividade como assunto mais explorado. De um ponto de vista ampliado, verificamos que diversos assuntos, teorias e conceitos presentes no estudo da Física Moderna podem ser encontrados e explorados nas várias modalidades artísticas existentes. Essa relação pode se mostrar de maneira direta, onde as obras apresentam um viés científico explícito, como as poesias presentes no artigo de Barja (2013), ou de maneira indireta, onde essa relação depende apenas da interpretação do leitor, sem ter uma relação com a ciência de forma explícita, como, por exemplo, um leitor leigo que observa o quadro "A desmaterialização do nariz de Nero" de Salvador Dalí.

Destacamos que o problema desta relação indireta se dá por ela restringir a Arte apenas como ferramenta de ensino, sendo utilizada como representação de algum elemento, fenômeno ou conceito científico, mesmo sem saber se os mesmos foram considerados no momento de sua confecção. Desse modo, não se torna possível realizar uma abordagem mais 
completa e contextualizada do assunto, não oferecendo ao aluno um ensino mais aprofundado das ligações existentes entre diferentes áreas de ensino e sobre a complexidade de nossa realidade.

A leitura dos artigos pertencentes à categoria de Propostas didáticas nos apresenta certas possibilidades de utilização das Artes no ensino de conteúdos de Física Moderna, sendo as modalidades artísticas usadas como recursos introdutórios ao assunto a ser explorado pelo professor, que pode realiza-lo de modo contextualizado.

Após explorar os artigos selecionados para a categoria de Abordagem teórica, percebemos a importância defendida pelos autores sobre as possibilidades de uso das prováveis relações entre as Artes e a Ciência no ensino de Física Moderna. Apesar de não apresentarem propostas didáticas, esses artigos se constituem como leituras para professores interessados em aprofundar e aplicar essa relação em sua prática profissional, até mesmo em seu aprendizado pessoal, visto que dão um panorama interessante sobre a junção dessas duas áreas de conhecimento.

A categoria de Experiência educacional nos fornece um panorama das propostas pedagógicas referentes à temática já realizada em sala de aula, encontrando tanto atividades concluídas como aplicações em andamento até a submissão dos artigos em questão. A leitura dessas publicações nos mostrou que essas aplicações ocorreram, em sua maioria, em turmas do ensino médio, sendo apenas dois deles aplicados em cursos de graduação. Todos os trabalhos analisados apresentam resultados satisfatórios em relação ao uso das Artes na compreensão de conceitos da Física Moderna.

Além de se usada, em sua maioria, como material introdutório e facilitador na compreensão de um assunto, as Artes também são utilizadas como atividades avaliativas, com o objetivo de que o aluno expresse seu entendimento sobre o conteúdo de maneira mais informal. As atividades, no geral, se mostram bem aproveitadas pelos professores, que exploram os materiais de forma criativa e instigam os alunos a construírem seus conhecimentos sobre os temas abordados.

Um ponto que consideramos importante de destacar é que a maioria dos artigos apresenta a produção artística como recurso facilitador no ensino de conteúdos de FMC. Entendemos que esse já é um grande passo na inovação do ensino de física nas instituições de ensino, porém acreditamos que essa relação pode ser apresentada de forma mais profunda ao retiramos das artes o caráter de ferramenta facilitadora e procurarmos trabalhar o contexto histórico tanto do conteúdo artístico quanto do conteúdo científico que se pretende ensinar.

Poucos são os artigos da amostra que apresentam essa relação de forma mais contextualizada, relacionando os conceitos estudados com os acontecimentos da época em que estavam sendo desenvolvidos. Que mostram como as técnicas artísticas auxiliaram no desenvolvimento científico e vice-versa, como foi exposto de forma breve no início deste trabalho.

O professor, ao escolher abordar certo conteúdo de forma interdisciplinar, não só entre Física e Arte, mas também, História, Geografia, Português, entre outros, deve entender 
como essa relação se constitui de modo mais aprofundado possível, para que o conteúdo de uma disciplina não seja apenas figurativo no ensino de outra.

Obter esse conhecimento e adaptá-lo para a sala de aula seriam os passos seguintes no caminho que percorremos para um ensino de Física diferenciado, principalmente como forma de abordar tópicos de FMC, visto que estes são os mais negligenciados no ensino médio.

\section{Considerações finais}

Este trabalho teve como incentivo explorar as potencialidades que a relação entre Arte e Ciência pode proporcionar para tornar o ensino mais contextualizado e significativo, visto que essas duas áreas partem do mesmo objeto de estudo, a natureza.

Nosso foco foi mais específico, explorar a relação entre a Física e a Arte no ensino de Física Moderna. A partir da busca de artigos e trabalhos já publicados sobre essa temática, procuramos compreender como essa relação está sendo estudada e utilizada no âmbito educacional. Assim, voltando ao questionamento inicial, podemos dizer que, em sua maioria, os artigos apresentam as modalidades artísticas apenas como ferramenta de ensino, utilizando-as como introdutórias a assuntos, como facilitadores de ensino ou como representação de objetos de estudos da Física Moderna. Poucos são os artigos que utilizam de modo mais contextualizado a ligação entre essas duas áreas, apresentando as características da sociedade à época dos conceitos estudados, quando fazem uso das artes pictóricas, das poesias, das músicas e dos filmes.

Consideramos que as propostas didáticas e as experiências educacionais expostas aqui são boas maneiras de tornar o ensino de Física diferenciado, saindo da rotina de gráficos e equações. As experiências educacionais também mostram, através de seus resultados, um aceitamento positivo da maioria dos alunos, que se apresentam mais dispostos e abertos a novas formas de aprendizagem. Os artigos com abordagem teórica constituem, para nós, materiais relevantes para aqueles que têm interesse em aprender mais sobre essa relação e servem como base para a criação de novas propostas didáticas.

Por fim, finalizamos este trabalho atingindo nosso objetivo de compreender como essa relação está sendo explorada no ensino de Física Moderna, entendendo que já temos um bom caminho percorrido na inserção da Arte na Física, mas que essa caminhada está longe de terminar, considerando que a Arte não deve ser apenas uma ferramenta facilitadora, mas que seja utilizada de modo contextualizado historicamente e socialmente, permitindo que o conhecimento adquirido pelo aluno o ajude a enxergar a realidade de maneira mais complexa.

\section{Agradecimentos}

O presente trabalho foi realizado com apoio da Coordenação de Aperfeiçoamento de Pessoal de Nível Superior - Brasil (CAPES) - Código de Financiamento 001. 


\section{Referências}

ALCANTARA, M. C.; BRAGA, M.; COSTA, M. F. S. Espelhos, lentes e pintura: Uma proposta de atividade baseada na obra de David Hockney. Física na Escola, v. 15, n. 1, 2017.

ANDRADE, R. R. D. de; NASCIMENTO, R. S.; GERMANO, M. G. Influências da teoria da relatividade na obra de Salvador Dalí. In: SIMPÓSIO NACIONAL DE ENSINO DE FÍSICA, XVI, 2005, Rio de Janeiro. Atas...

ANDRADE, R. R. D. de; NASCIMENTO, R. S.; GERMANO, M. G. Influências da Física moderna na obra de Salvador Dalí. Caderno Brasileiro de Ensino de Física, v. 24, n. 3, p. 400-423, dez. 2007.

BARBOSA-LIMA, M. C.; QUEIROZ, G.; SANTIAGO, R. Ciência e arte: Vermeer, Huygens e Leeuwenhoek. Física na Escola, v. 8, n. 2, 2007.

BARJA, P. R. Poesia e física: multiplicando a beleza das coisas. In: SIMPÓSIO NACIONAL DE ENSINO DE FÍSICA, XX, 2013, São Paulo. Atas...

CACHAPUZ, A. F. Arte e Ciência no ensino das ciências. Interacções, n. 31, p. 95-106, 2014.

CARUSO, F.; FREITAS, N. de. Física Moderna no Ensino Médio: o espaço-tempo de Einstein em tirinhas. Caderno Brasileiro de Ensino de Física, v. 26, n. 2, p. 355-366, ago. 2009.

CARVALHO, S. H. M. de; ZANETIC, J. Ciência e Arte, Razão e Imaginação: um projeto de ensino de física moderna para alunos do ensino médio. In: SIMPÓSIO NACIONAL DE ENSINO DE FÍSICA, XVI, 2005, Rio de Janeiro. Atas...

EICHLER, T. Z. N.; EICHLER, M. L. A rede social Pinterest e a curadoria na educação científica: O exemplo do surrealismo de Dalí. In: ENCONTRO NACIONAL DE PESQUISA EM EDUCAÇÃO EM CIÊNCIAS, XI, 2017, Universidade Federal de Santa Catarina, Florianópolis. Atas...

FERNANDES, R. F. A. M.; PIRES, F. F.; FORATO, T. C. M.; SILVA, J. A. da Pinturas de Salvador Dalí para introduzir conceitos de Mecânica Quântica no Ensino Médio. Caderno Brasileiro de Ensino de Física, v. 34, n. 2, p. 509-529, ago. 2017.

GALILI, I. On the Power of Fine Arts Pictorial Imagery in Science Education. Science \& Education, v. 22, p. 1911-1938, 2013.

GIL, A. C. Como elaborar projetos de pesquisa. 4. ed. São Paulo: Editora Atlas S. A., 2002. $176 \mathrm{p}$.

GOMES, E. F.; PIASSI, L. P.; FERNANDES, J. Perspectivas socioculturais no uso da canção no ensino de física: utilizando o rock para debater questões inerentes às missões espaciais e 
aos paradoxos temporais. In: SIMPÓSIO NACIONAL DE ENSINO DE FÍSICA, XX, 2013, São Paulo.

GOMES, E. F.; PIASSI, L. P. C. Ciência, mídia e educação: possíveis confluências no ensino de física. In: SIMPÓSIO NACIONAL DE ENSINO DE FÍSICA, XXI, 2015, Uberlândia.

GOMES, T. C.; GIORGI, C. A. G. Di; RABONI, P. C. A. Física e pintura: dimensões de uma relação e suas potencialidades no ensino de física. Revista Brasileira de Ensino de Física, v. 33, n. 4, p. 4402, 2011.

GUERRA, A.; BRAGA, M.; REIS, J. C. Teoria da relatividade restrita e geral no programa de mecânica do ensino médio: uma possível abordagem. Revista Brasileira de Ensino de Física, v. 29, n. 4, p. 575-583, 2007.

MACHADO, D.I.; NARDI, R. Avaliação do ensino e aprendizagem de física moderna e contemporânea no ensino médio. In: ENCONTRO NACIONAL DE PESQUISA EM EDUCAÇÃO EM CIÊNCIAS, IV, 2003, Toledo, PR.

MENEZES, A. M. S.; MORAES, A. G. Física e Literatura: intersecções possíveis em sala de aula. In: SIMPÓSIO NACIONAL DE ENSINO DE FÍSICA, XVIII, 2009, Vitória, ES.

MONTEIRO, M.A.; NARDI, R.; BASTOS FILHO, J.B. Dificuldades dos professores em introduzir a física moderna no ensino médio: a necessidade de superação da racionalidade técnica nos processos formativos. In: NARDI, R. (Org). Ensino de ciências e matemática, I: temas sobre a formação de professores. São Paulo: Editora UNESP; São Paulo: Cultura Acadêmica, 2009. 258 p. Disponível em: <http://books.scielo.org/id/g5q2h/pdf/nardi9788579830044-10.pdf>. Acesso em: 03 jul. 2018.

NORY, R. M.; ZANETIC, J. O teatro e a física: a cena que não entra em sala. In: SIMPÓSIO NACIONAL DE ENSINO DE FÍSICA, XVI, 2005, Rio de Janeiro.

NUNES, A. L.; TEIXEIRA, G. A. Ciência e Arte: Razão e Sensibilidade. In: SIMPÓSIO NACIONAL DE ENSINO DE FÍSICA, XVII, 2007, São Luís, MA.

OLIVEIRA, F. F. de; VIANNA, D. M.; GERBASSI, R.S. Física moderna no ensino médio: o que dizem os professores. Revista Brasileira de Ensino de Física, v. 29, n. 3, p. 447-454, 2007.

OLIVEIRA, L. M. Estabelecendo o diálogo entre as duas culturas: imaginação e criatividade aliadas ao ensino de física. In: SIMPÓSIO NACIONAL DE ENSINO DE FÍSICA, XXI, 2015, Uberlândia, MG.

OLIVEIRA, L. M.; GOMES, M. L. A. Einstein e a Relatividade entram em cena: diálogos sobre o teatro na escola e um ensino de Física criativo. Caderno Brasileiro de Ensino de Física, v. 33, n. 3, p. 943-961, dez. 2016. 
PINTO, A. C.; ZANETIC, J. É possível levar a Física Quântica para o Ensino Médio? Caderno Catarinense de Ensino de Física, v. 16, n. 1, p. 7-34, abr. 1999.

RAMOS, J. E. F.; PIASSI, L. P. O insólito e a física moderna: interfaces didáticas do conto fantástico. Ciência e Educação, Bauru, v. 23, n. 1, p. 163-180, 2017.

REIS, J. C.; GUERRA, A.; BRAGA, M. Ciência e arte: relações improváveis? História, Ciências, Saúde - Manguinhos, v. 13, (suplemento), p. 71-87, outubro 2006.

RICARDO, E. C.; FREIRE, J. C. A. A concepção dos alunos sobre a física do ensino médio: um estudo exploratório. Revista Brasileira de Ensino de Física, v. 29, n. 2, p. 251-266, 2007.

ROSSI, P. Coisas jamais vistas. In: ROSSI, P. (Org). O nascimento da Ciência Moderna na Europa. São Paulo: EDUSC, 2001.

SANTOS, G. L.; TEIXEIRA, R. R. P. Ciência, cinema e macacos. In: SIMPÓSIO NACIONAL DE ENSINO DE FÍSICA, XX, 2013, São Paulo.

SNOW, C. P. As duas culturas e uma segunda leitura. São Paulo: Edusp, 1995. 128 p.

SOUZA, A. R. de; NEVES, L. A. S. O livro paradidático no ensino de Física - uma análise fabular, científica e metafórica da obra Alice no País do Quantum: A Física Quântica ao alcance de todos. Caderno Brasileiro de Ensino de Física, v. 33, n. 3, p. 1145-1160, dez. 2016.

ZANETIC, J. Física e Arte: uma ponte entre duas culturas. Pro-Posições, v. 17, n. 1. p. 49, jan./abr. 2006. 